\title{
Chronomics, human time estimation, and aging
}

\author{
Franz Halberg \\ Robert B Sothern \\ Germaine Cornélissen \\ Jerzy Czaplicki' \\ Halberg Chronobiology Center, \\ University of Minnesota, Minneapolis, \\ MN, USA; 'Institut de Pharmacologie \\ et de Biologie Structurale CNRS, \\ Université Paul Sabatier, Toulouse, \\ France
}

Background: Circadian rhythm stage affects many outcomes, including those of mental aging.

Methods: Estimations of 1 minute $\sim 5$ times/day for a year, 25 years apart, by a healthy male biomedical scientist (RBS), are analyzed by the extended cosinor.

Results: Cycles of a half-week, a week, $\sim 30$ days, a half-year and a year, in self-assessed 1-minute estimation by RBS between 25 and 60 years of age in health, are mapped for the first time, compared and opposite effects are found. For RBS at $60 \mathrm{vs}$ at 25 years of age, it takes less time in the morning around 10:30 $(\mathrm{P}<0.001)$, but not in the evening around 19:30 $(\mathrm{P}=0.956)$, to estimate 1 minute.

Discussion: During the intervening decades, the time of estimating 1 minute differed greatly, dependent on circadian stage, being a linear decrease in the morning and increase in the evening, the latter modulated by a $\sim 33.6$-year cycle.

Conclusion: Circadian and infradian rhythm mapping is essential for a scrutiny of effects of aging. A 30-day and a circannual component apparent at 25 years of age are not found later; cycles longer than a year are detected. Rhythm stages await tests as markers for timing therapy in disease.

Keywords: circadian rhythm, mental function, time estimation

\section{Introduction}

Chronomics, the study of time structures (Figure 1) attempts to resolve, as a function of the density and length of a time series, trends such as those with age, in the context of other elements of chronomes such as a broad spectrum of rhythms (Halberg et al 2003a) for which the length of the series is critical (and/or deterministic chaos, the resolution of which, in the broad chronomic context, depends on the density of the time series [Otsuka et al 1997; Burioka et al 2005], beyond our scope herein). We explore circadian and infradian rhythms in time estimation (TE), having shown that the stage of the former is essential for the assessment of the latter in the case of a half-year-long spectral component probably related to geomagnetics in human systolic blood pressure (SBP) (Tarquini et al 1997; Halberg et al 2001a; Cornélissen et al 2002; Sothern et al 2006). We here ask whether changes with age in a mental function, such as the TE of an 1-minute duration, also differ as a function of circadian stage. Our test of mental functioning for precisely timed action is performed inexpensively, without the need for bulky instrumentation beyond a stopwatch. The test is quick and easily repeated, and may also tell us whether and, if so, when one aspect of subjective time - one minute - may change with age. What is particularly important, the circadian components here mapped could serve as a marker for interventions, therapeutic or other.

\section{Background}

TE is a basic and critical feature and index of mental processes (Piaget 1946; Fraisse 1963; Geissler and Reschke 1987). A circadian rhythm characterizes several approaches to estimating 2 minutes under conditions of 24-hour synchronization with (Stephens 


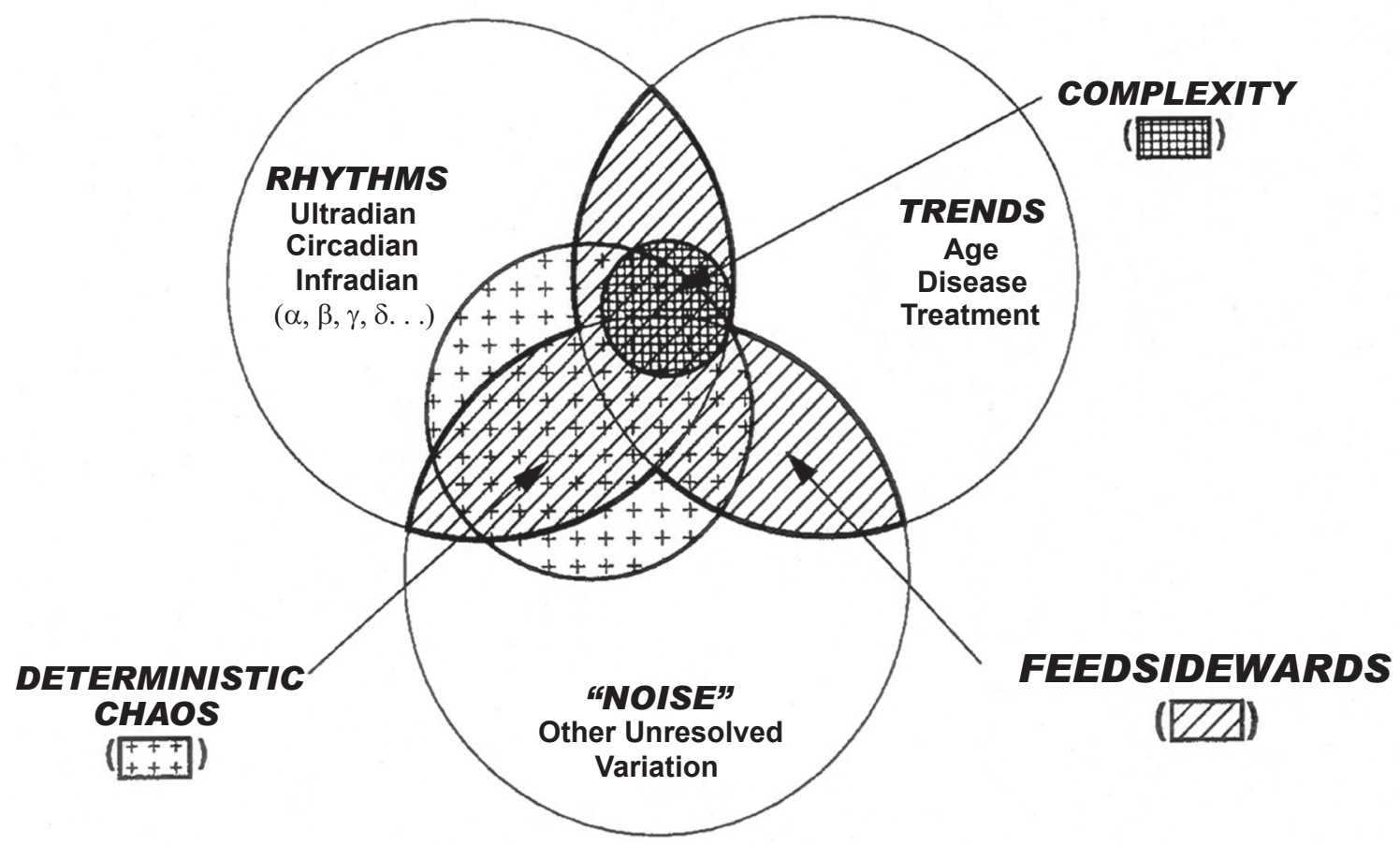

Figure I Sketch of the measurable time structure (chronome, of an environmental and/or biospheric variable) consisting of endpoints of rhythms, trends and deterministic chaos, resolvable as a function of the length and density of a time series, respectively, and any residual variation.

and Halberg 1965) or desynchronization from (Halberg et al 1965; Siffre et al 1966; Halberg and Reinberg 1967; Ghata et al 1968; Halberg 1968; Wever 1979) a societal routine. The circadian rhythm persists under conditions of isolation from society with a concomitant decrease of the ratio "subject time/environmental time" (cf. Tables 1 and 2 as well as Figures $2 \mathrm{a}$ and $2 \mathrm{~b}$ ). Such results extend earlier pioneering studies by MacLeod and Roff (1935) and were confirmed and extended by follow-ups that also considered putative effects of cosmic factors (Hillman et al 1994; Halberg et al 1998) and infradians (Sanchez de la Peña et al 1989), among others. Whether or not a change in ratio of subjective/ environmental time during isolation relates to the lengthening of the desynchronized circadian rhythm in 2-minute TE and in other variables, noted in most humans studied thus far (Wever 1979), remains to be investigated in a broader context (Fraisse 1963; Geissler and Reschke 1987; Glicksohn 1992; Halberg et al 2001a; Eagleman et al 2005). For example, when the subject of this paper (RBS) spent 19 days in social isolation near the beginning of his 40 -year self-measurement project, the period of his circadian rhythm in 2-minute time estimation increased $\sim 4 \%$, from 24.0 to 24.9 hours, while the 24-hour mean increased about $22 \%-25 \%$, from about $150 \mathrm{~s}$ to $188 \mathrm{~s}$ (unpublished observations [cf. Halberg et al 1972]). Both a decrease in circadian amplitude during isolation and an increase in circadian amplitude after isolation are seen in Figure 2c for the rhythm in core temperature (top) and 2-minute estimation (bottom), along with a delaying drift of the acrophases due to a lengthening of period.

Glicksohn (1992) "hypothesized that the more varied the sensory environment (ie, perceptual overload versus perceptual deprivation), the longer the time that is verbally estimated, and the shorter the time estimation obtained by the method of production". His data on 96 subjects exposed to various combinations of auditory and visual stimulation gathered by the latter method agreed, but not those with the former method. He concluded that "visual and auditory stimulation interact in their production of an altered sensory environment, and that the rate of functioning of the cognitive timer is environment dependent." Eagleman and colleagues (2005) review "New discoveries in psychophysics, electrophysiology, imaging, and computational modeling [that] are contributing to an emerging picture of how the brain processes, learns, and perceives time", emphasizing that "Most of the actions our brains perform on a daily basis, such as perceiving, speaking, and driving a car, require timing on the scale of tens to hundreds of milliseconds." Sothern and colleagues (2007) most recently found a near-transyearly period, $\tau(1.00$ year $<[\tau-\mathrm{CI}\{95 \%$ confidence interval $\}]<\tau+\mathrm{CI}]<1.20$ years), and several far-transyearly $\tau_{\mathrm{s}}(1.2$ years $\leq[\tau-\mathrm{CI}]<[\tau+\mathrm{CI}]<1.9$ years) in 1-minute TE (about 5 times a day for 35 years) as a magnetoperiodism, with a differential congruence of these 
Table I Indices used for evaluating circadian rhythms in human estimations of spans ranging from minutes to hours or days - applicable to "intuitive" (empty) estimations or to "rational" ones (eg, by counting)

\begin{tabular}{|c|c|c|c|}
\hline Index N & Units entering index & $\begin{array}{l}\text { Relation of environmental time to } \\
\text { "subject" time when given }\end{array}$ & Examples \\
\hline & & ESTIMATION OF "SHORT DURATIONS" & \\
\hline I & $\begin{array}{l}\text { Seconds elapsed (during estimation) } \\
\text { (seconds estimated not stated) }\end{array}$ & $\begin{array}{l}\text { Environment seconds only (corresponding } \\
\text { to fixed } \mathrm{N} \text { of subject seconds) }\end{array}$ & $\begin{array}{l}\text { eg, } 240 \text { seconds (elapsed during } \\
\text { count from } 1-120 \text { ) }\end{array}$ \\
\hline 2 & $\begin{array}{l}\text { Seconds elapsed (during estimation) } \\
\text { Seconds estimated (by subject) }\end{array}$ & $\begin{array}{l}\text { Environment seconds (or minutes) } \\
\text { Subject seconds (or minutes) }\end{array}$ & eg, $\frac{240}{120}=2$ (seconds per count) \\
\hline 3 & $\begin{array}{l}\text { Seconds estimated (by subject) } \\
\text { Seconds elapsed (during estimation) }\end{array}$ & $\begin{array}{l}\text { Subject seconds } \\
\text { Environment seconds } \\
\text { ESTIMATION OF “LONGER DURATIONS" }\end{array}$ & eg, $\frac{120}{240}=0.5$ (counts per second) \\
\hline 4 & $\begin{array}{l}\text { Hours *thought to be elapsed (by subject) } \\
\text { Hours *elapsed in environment }\end{array}$ & $\begin{array}{l}\text { Subject hours } \\
\text { Environment hours }\end{array}$ & eg, $\frac{1}{2}=0.5$ \\
\hline 5 & $\begin{array}{l}\text { Days thought to be elapsed (by subject) } \\
\text { Days elapsed in environment }\end{array}$ & $\begin{array}{l}\text { Subject days } \\
\text { Environment days }\end{array}$ & eg, $\frac{40}{60}=0.667$ \\
\hline
\end{tabular}

Notes: *Converted to minutes prior to division; Index I is simple to record, but has shortcomings: (a) The index does not indicate the time span believed by the subject to have elapsed ("subject time"); it denotes only a span of environmental time, corresponding to a (not stated) span estimated by the subject. Therefore, the time estimated (ie, the equivalent of subject time) must be given separately, with each value. For example, in using the index, one must separately specify the estimation of I 20 secs (of subject time) for which a given interval, say of 240 secs (environment time) has elapsed during a test. (b) Since, as indicated above, index I does not establish a relation between subject time (not explicitly contained in the index) and environment time, it is not comparable, without transformation, among tests involving even slight differences in the time span estimated by a given subject. (c) The index is inversely related to the passage of subjective time; it will assume a higher value when "subject time" passes more slowly than "environment time" and vice versa. Thus, the index is physiologically somewhat confusing in that a number of other biological variables with which this index might be compared, such as heart rates, assume higher values when a process speeds up and lower ones when it slows down. Shortcomings (a) and (b) above do not apply to indices $2-5$. None of the above-listed shortcomings applies to indices $3-5$, all constituting ratios of Subject time

near- and far-transyear periods with the periods of cycles in the solar wind's speed and geomagnetics. Here we focus on the photic circadian and other rhythm-stage dependence of changes in 1-minute TE and on any effects of age.

\section{Subject and methods}

For 3.5 decades, 1 minute was estimated by counting two to seven times daily (on the average about 5 times/day), by a clinically healthy man (RBS), who started estimating 2 minutes by counting at $\sim 20.5$ years of age in 1967 . In view of differences between TE of 2 minutes, performed at the start of monitoring for $\sim 3$ years and subsequent 1-minute TE continued a year later for 3.5 decades, only data from the longer 35-year record (of 1-minute TE) are here considered. Data were analyzed spectrally, by the extended linear-nonlinear cosinor (Halberg 1980; Cornélissen and Halberg 2005; Refinetti et al 2007) with

Table 2 Time estimation of four human adults in the absence of known time cues

\begin{tabular}{|c|c|c|c|c|c|c|c|c|c|c|}
\hline \multirow[b]{2}{*}{$\begin{array}{l}\text { Procedure } \\
\text { (interval) }\end{array}$} & \multirow[b]{2}{*}{ Index evaluated } & \multicolumn{2}{|l|}{ EH (M) } & \multicolumn{2}{|l|}{ MS (M) } & \multicolumn{2}{|l|}{ TS (M) } & \multicolumn{3}{|l|}{ JL (F) } \\
\hline & & $\begin{array}{l}N \text { of obs } \\
\text { ( } N \text { of days) }\end{array}$ & $\begin{array}{l}\text { R } \\
( \pm \text { SD) }\end{array}$ & $\begin{array}{l}N \text { of obs } \\
\text { ( } N \text { of days) }\end{array}$ & $\begin{array}{l}\text { R } \\
( \pm \text { SD })\end{array}$ & $\begin{array}{l}N \text { of obs } \\
\text { ( } N \text { of days) }\end{array}$ & $\begin{array}{l}\text { R } \\
( \pm \text { SD) }\end{array}$ & $\begin{array}{l}\mathbf{N} \text { of obs } \\
\text { ( } N \text { of days) }\end{array}$ & $\begin{array}{l}\mathbf{R} \\
( \pm \mathbf{S D})\end{array}$ & Isolation \\
\hline \multirow[t]{2}{*}{$\begin{array}{l}\text { "Intuitive" } \\
\text { (empty) }\end{array}$} & $\mathrm{R}^{*}=\frac{\mathrm{S} \text { months }}{\mathrm{E} \text { months }}$ & & & $\begin{array}{l}2 \\
(59)\end{array}$ & 0.58 & $\begin{array}{l}2 \\
(12 \mid)\end{array}$ & 0.54 & $\begin{array}{l}2 \\
(87)\end{array}$ & 0.84 & \\
\hline & $R=\frac{\text { Shours }}{\text { Ehours }}$ & $\begin{array}{l}108 \\
\text { (II) }\end{array}$ & $\begin{array}{l}\text { I.0I } \\
( \pm 0.17)\end{array}$ & $\begin{array}{l}231 \\
(59)\end{array}$ & $\begin{array}{l}0.56 \\
( \pm 0.28)\end{array}$ & $\begin{array}{l}536 \\
(125)\end{array}$ & $\begin{array}{l}0.66 \\
( \pm 0.31)\end{array}$ & $\begin{array}{l}294 \\
(88)\end{array}$ & $\begin{array}{l}0.45 \\
( \pm 0.25)\end{array}$ & Yes \\
\hline \multirow[t]{2}{*}{$\begin{array}{l}\text { Rational (filled, } \\
\text { ie, counting } \\
\text { from I to I20) }\end{array}$} & $\mathrm{R}=\frac{\mathrm{S} \text { seconds }}{\mathrm{E} \text { seconds }}$ & & & $\begin{array}{l}168 \\
(59)\end{array}$ & $\begin{array}{l}0.67 \\
( \pm 0.12)\end{array}$ & $\begin{array}{l}310 \\
(125)\end{array}$ & $\begin{array}{l}0.92 \\
( \pm 0.09)\end{array}$ & $\begin{array}{l}175 \\
(88)\end{array}$ & $\begin{array}{l}0.62 \\
( \pm 0.12)\end{array}$ & \\
\hline & & & & & & $\begin{array}{l}161 \\
(31)\end{array}$ & $\begin{array}{l}0.96 \\
( \pm 0.08)\end{array}$ & $\begin{array}{l}196 \\
(31)\end{array}$ & $\begin{array}{l}0.88 \\
( \pm 0.09)\end{array}$ & No \\
\hline
\end{tabular}

S (Subject) time

Notes: " $\mathrm{R}=\mathrm{E}$ (Environment) time ; these ratios are in italics; they represent means, except for those in first row of table; Means and standard deviations in table refer to data previously "clipped" to mean $\pm 3 \mathrm{SD}$; iterative clippings until 4 decimal places remain the same.

Abbreviations: $\mathrm{S}$ = subjective; $\mathrm{E}$ = environmental. 


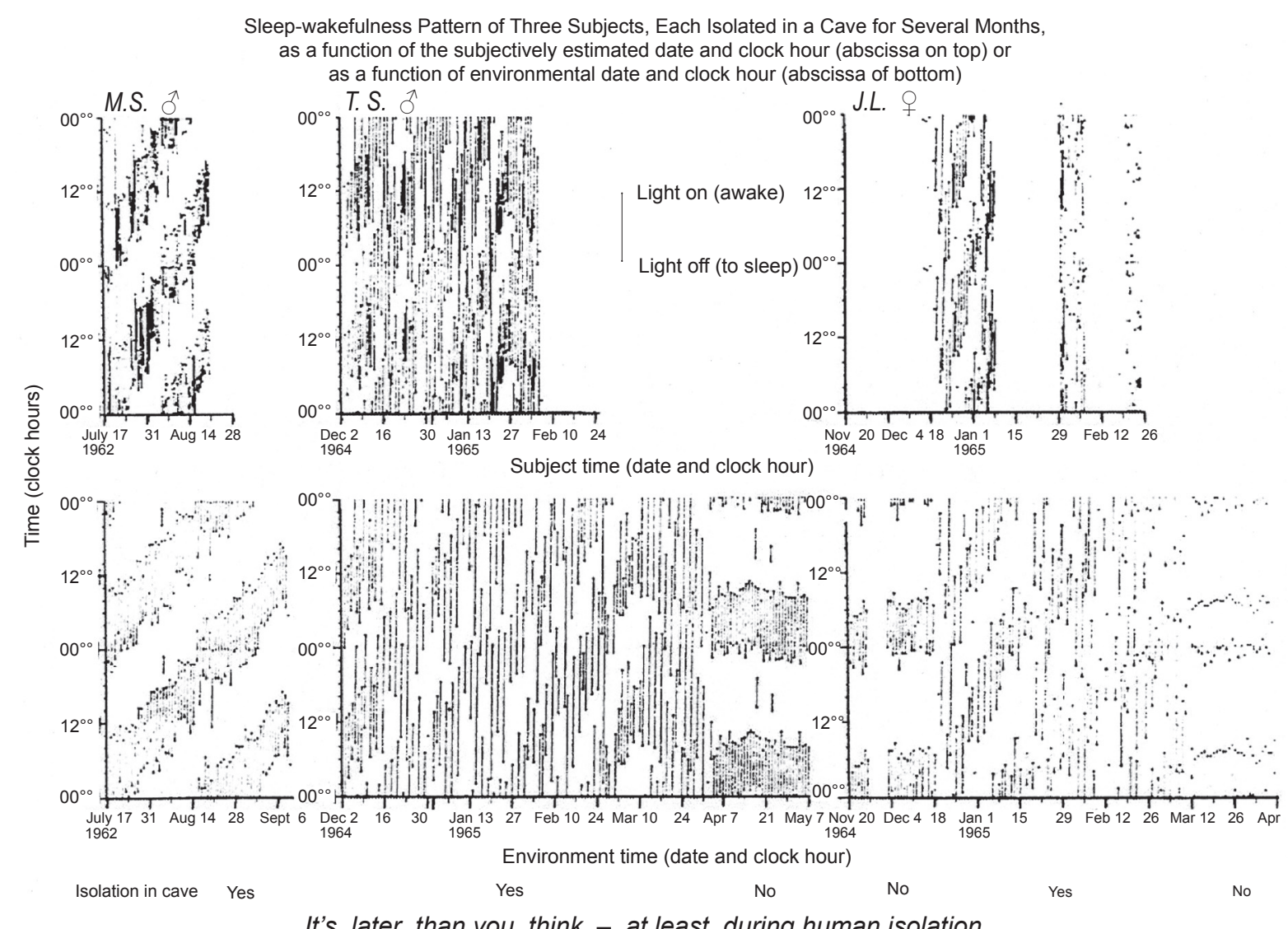

It's later than you think - at least during human isolation

Figure 2A Macroscopic records of the effect of human isolation upon the sleep-wakefulness rhythm. For the individual, the subjectively estimated time of day and calendar date differ greatly in the isolation of a cave (upper row) from that recorded in societal life (lower row). Waking and sleeping of 3 subjects is plotted on top as a function of subjectively estimated time in isolation and at the bottom as complemented by one-way (cave-to-surface only) telephone to a team outside a cave by Michel Siffre (MS) and two other subjects, TS and JL (top). Note that on returning to society, all 3 subjects thought they had spent much less time in isolation than they actually had. JL readjusted her clock-hour and calendar-date estimate following each menstruation, hence the gaps in the figure on the top right (see also Table 2).

parameter tests (Bingham et al 1982; cf. Halberg et al 2003a) and by comparing the first and the last year's original data in 8 time-of-day bins of 3 hours each with Student's t-test and all 8 timepoints by a paired t-test.

\section{Results}

In Figure 3, the periodogram of RBS's data is plotted linearly in frequency, yet with periods given on top for each half of the figure, the upper half summarizing results at 25 years of age, and the lower one at 60 years of age. The original ordinate at the bottom of each, the upper and lower halves, is given on the right. In the insert of each half, the ordinate is truncated to prevent the dominating circadian from obscuring lower-than-circadian frequencies (infradians). The inserts show that with advancing age (lower vs upper half), some frequencies differ in prominence. While a circaseptan and a circasemiseptan component are detected with statistical significance at both ages, a 30-day component is detected prominently only at the younger age. At 60 years of age, a 1-year component's prominence is replaced by that of a half-yearly component, probably of geomagnetic (nonphotic) origin (Cornélissen et al 2002).

Figure 4 provides a highly qualified yet clear answer to the question whether there is an acceleration of the subjective "minute" with age in RBS. This figure stacks data in two chronograms along the 24-hour scale, each summarizing a year's data 35 years apart, at 25 vs 60 years of age, respectively. Without extrapolating to other subjects (Halberg et al 1981) and/or to the intervening years, admittedly great limitations, both the (sparsely documented) maxima and some of the (solidly documented) minima (numbers of TE at each time are given in parentheses) are numerically lower during year 35 than during the first year (Figure 4), ie, at 60 vs 25 years of age, suggesting acceleration. Figure 4 shows further that even if overall the time-structure-adjusted mean (MESOR) is numerically lower at an advanced age, the demonstration of an age change is not possible on this basis $(\mathrm{P}=0.300)$. A circadian stage-dependence in Figure 4 is found by Student t-tests that 


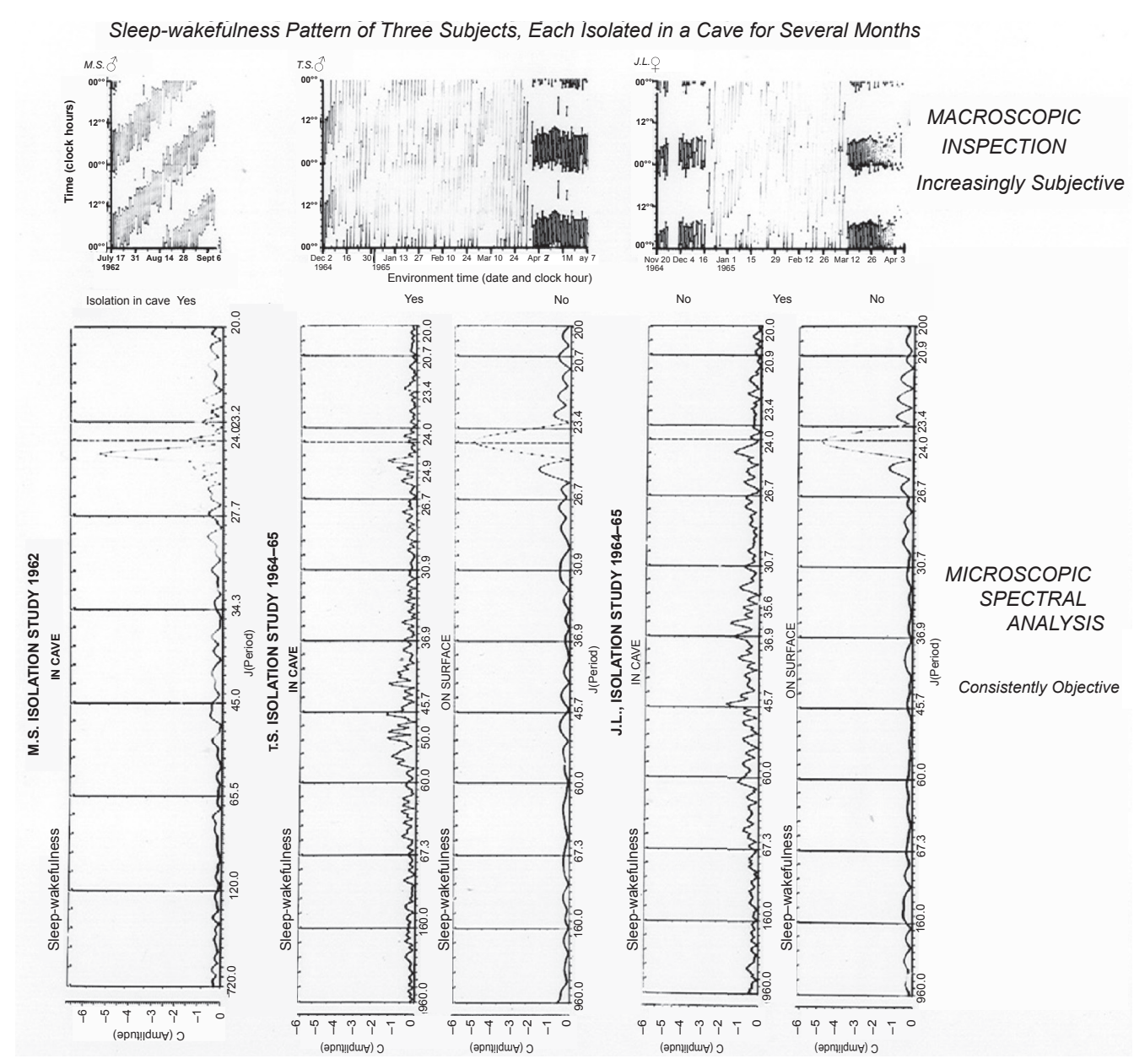

Figure 2B The amplitude of a circadian rhythm in a mental function, time (2-minute) estimation, is much smaller under conditions of desynchronization vs. that under 24-hour synchronized conditions. Note that in all subjects, during isolation, there is a peak in the spectrum away from the vertical line that corresponds to exactly 24 hours. In TS and $\mathrm{JL}$, who had continued to record sleep-wakefulness during the days after isolation, the amplitude is much smaller in isolation than under a societal routine.

show an aging effect in RBS to be not demonstrable at certain circadian stages, while it is statistically highly significant at other times of day; each result, that around 10:30 vs that at 19:30, is documented with relatively ample data.

\section{Discussion}

These results, albeit amply documented for RBS, cannot be extrapolated to others. In another case, HL, a physician with aldosteronism, the estimation of 2 minutes took longer at 63 years of age than it did at 53 years, as if time passed more slowly in this particular elderly man (Halberg et al 1981). While in HL the change during a decade seems to be linear, it was nonlinear over several decades in the yearly and transyearly amplitudes of RBS' heart rates (HR) (Sothern et al 2004) and what it was in TE remains to be assessed.

Differences in "age trends" assessed for RBS and HL may perhaps be reconciled, at least in part, by the presence of low-frequency cycles. In the case of RBS, an about 26-year cycle is detected for 1-minute time estimation. Even decade-long records may thus exhibit either an increasing or a decreasing trend depending on when during this about 26-year cycle monitoring took place. A similar situation was encountered in a 15-year record of urinary excretion of 17-ketosteroids characterized by an about 10 -year cycle (Halberg et al 2001b).

In the case of RBS, subjective time elapsed during the 19 days of isolation was shorter by 17.5 hours or $\sim 4 \%$. This is contrasted with 2-minute time estimation by RBS that was increased by $25 \%$ from $\sim 150$ to $\sim 188 \mathrm{~s}$, suggesting a dissociation between short-term and long-term time perception, the difference along the two time scales possibly accounted for, at least in part, by the rest-activity cycle, which provides an important clue of elapsed time along the scale of days.

Differential congruence of periods $(\tau s)$ in helio- and/or geomagnetics and in human psychophysiology is also 
Oral temperature (top) and 2-minute time estimation (bottom) of a clinically healthy man (RBS) 3 weeks before and after 19 days in isolation*

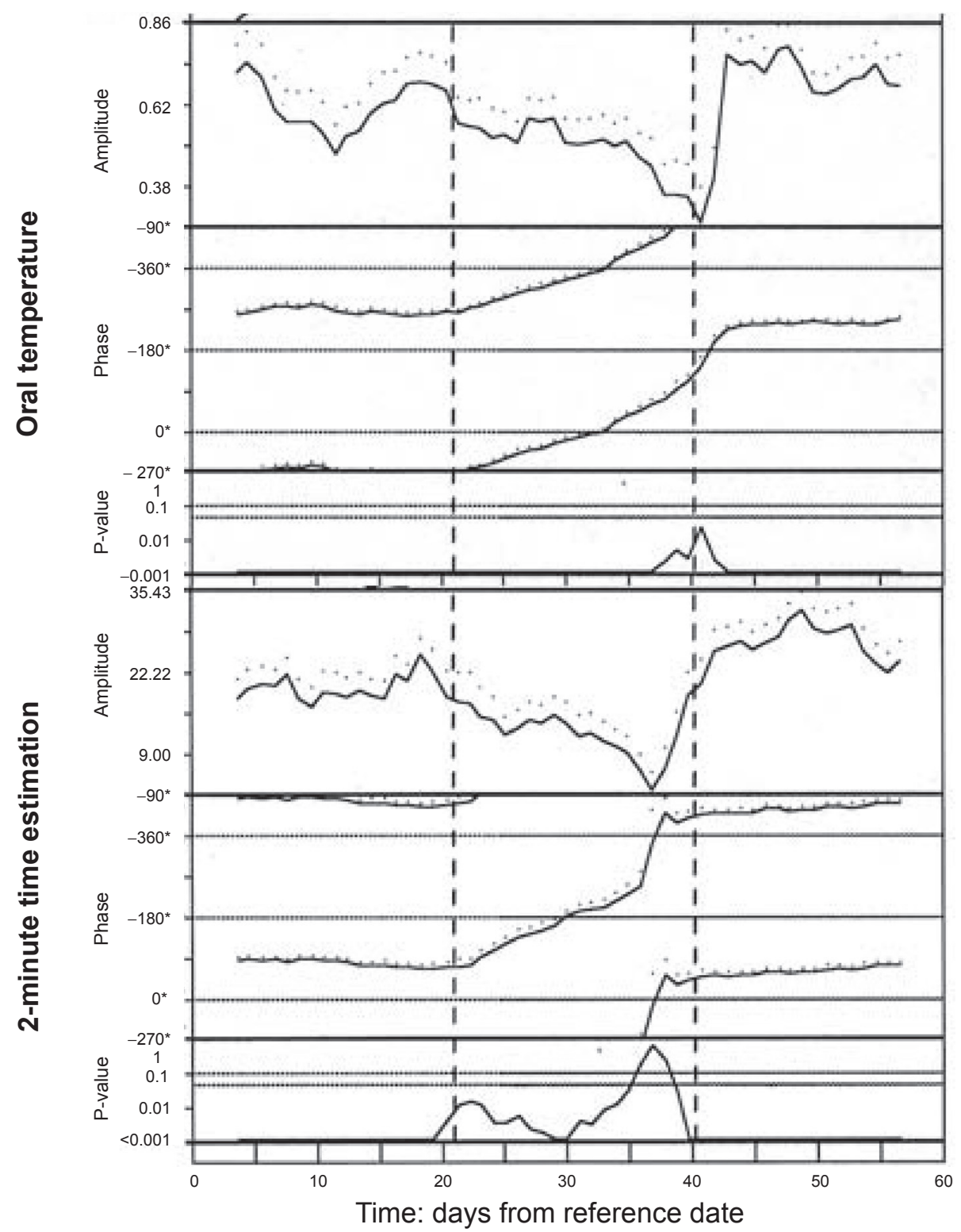

*Isolation began Sept 9, 1967 at 16:20 h and ended Sept 27, 1967 at 09:30 h (vertical dashed lines).

Serial section

\# Points: $\begin{aligned} & 489 \text { (top) } \\ & 488 \text { (bottom) }\end{aligned}$

Init. Date: 196708190000

Ref. time: 196708190000
Fitted components: 24.00 hours (h)

\begin{tabular}{|c|c|}
\hline Actual period: $\begin{array}{l}24.7 \mathrm{~h} \text { (top) } \\
24.9 \mathrm{~h} \text { (bottom) }\end{array}$ & Stabillty: $94.5 \%$ \\
\hline Interval: 168.000 & Latency: $0.0 \%$ \\
\hline Increase: 24.000 & Persistence: 60.0 \\
\hline
\end{tabular}

Figure 2C Chronomic serial sections of oral temperature and 2-minute estimations show time courses during isolation (as compared to before and after isolation) of a gradually decreasing amplitude and a delaying phase. The delaying phase corresponds to a lengthened period. The interval used for analysis (of I68 hours) involves, before and after the transitions, the use of some data from before and after isolation and shows, for time estimation but not for oral temperature, a spurious anticipatory amplitude rise before the end of the isolation span. 
documented for RBS assessed (by overlying or overlapping $95 \%$ confidence intervals) of $\tau$ s found in a mental function (1-minute TE) and in SBP and HR in about 4 decades of around-the-clock self-measurements (Sothern et al 2007). A combination of the extended cosinor by nonlinear analyses complemented by a population-mean cosinor summarizes the same series analyzed in consecutive subsections. There are corresponding $\tau \mathrm{s}$ in TE, SBP and HR themselves and in the spectrum of solar wind speed and in geomagnetics (aa index) for several orderingly statistically significant peaks between trial $\tau$ s of 2.0 and 0.7 years; this congruence differs among variables and $\tau$ s involved; it is differential. 5 of 8 SBP peaks are congruent with the solar wind in the spectral window examined at $\tau$ s different from a calendar year, as are 3 of the 4 SBP peaks that are congruent with geomagnetics. Congruence of SBP with magnetoperiodisms occurs in the presence of a large photoperiodic annual component in SBP. Congruence of $\tau$ s with solar wind is 3 out of 7 for HR and 5 out of 10 for TE, and with geomagnetics it is 2 out of 7 for HR and 4 out of 10 for TE. Different physiological variables and even the same variable's different spectral components may be influenced by different environmental $\tau$ s. While no congruence in all 5 variables was seen, all 3 psychophysiological variables were congruent with Richardson's $\sim 1.3$-year oscillation in solar wind speed during the span of RBS's data. Congruence among an as-yet

Spectral Window of 1-minute Time Estimation* by Clinically Healthy Man (RBS) Assessed

During First (top) and Last (bottom) Year of 35-year Record

Year 1 ( 25 years of age at start)

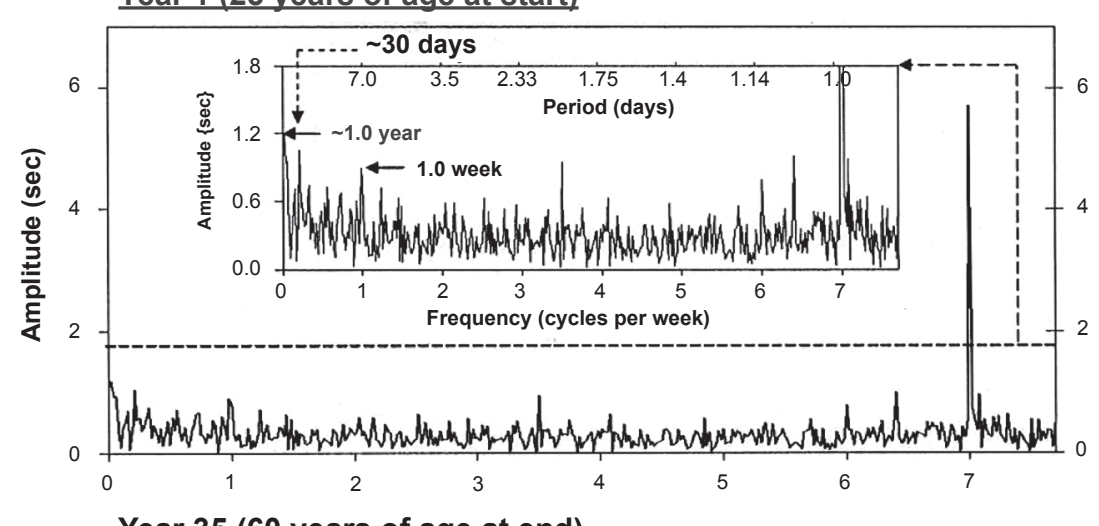

Year 35 (60 years of age at end)

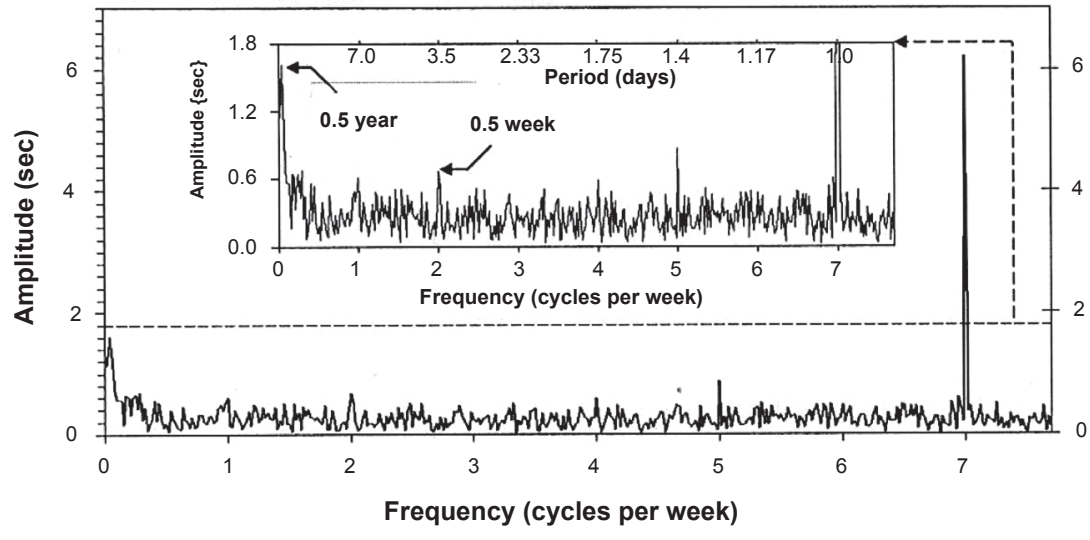

\begin{abstract}
*Original self-measurements (about $5 /$ day) analyzed by least squares spectra in the frequency range from one cycle in 52 weeks (or about 1 year; left on abscissa) to 0.13 cycle per week (or 21.84 hours; right on abscissa), using integer harmonics. Prominence of circadian component apparent from tall peak at 7 cycles per week (24-hour period)l; Amplified vertical scale (inserts) reveals with truncated circadian, the presence of other components. Note the frequency multiplication of the circannual and circaseptan components between years 1 and 35 , and the presence of an about 30-day component in the first year.
\end{abstract}

Figure 3 The large amplitude of the 24-hour synchronized circadian component dominates the spectrum of the estimation of I minute by RBS, a clinically healthy man at both 25 (top) and 60 years of age (bottom), as visualized by the abscissa at the bottom, showing cycles per week, with 7 cycles = I day, a very sharp peak at each age. In the inserts of each half, the period is also given. The 24-hour synchronized component stands out clearly, as it does in other cases under conditions of ordinary life (see also Figure 2 b's spectrum), as well as in isolation from society in caves, albeit with a much lesser amplitude, Figure $2 \mathrm{~b}$. 


\section{Circadian Stage-Dependence of Age-Related Difference \\ in 1-minute Time Estimation \\ (RBS: M, 25y at start)}

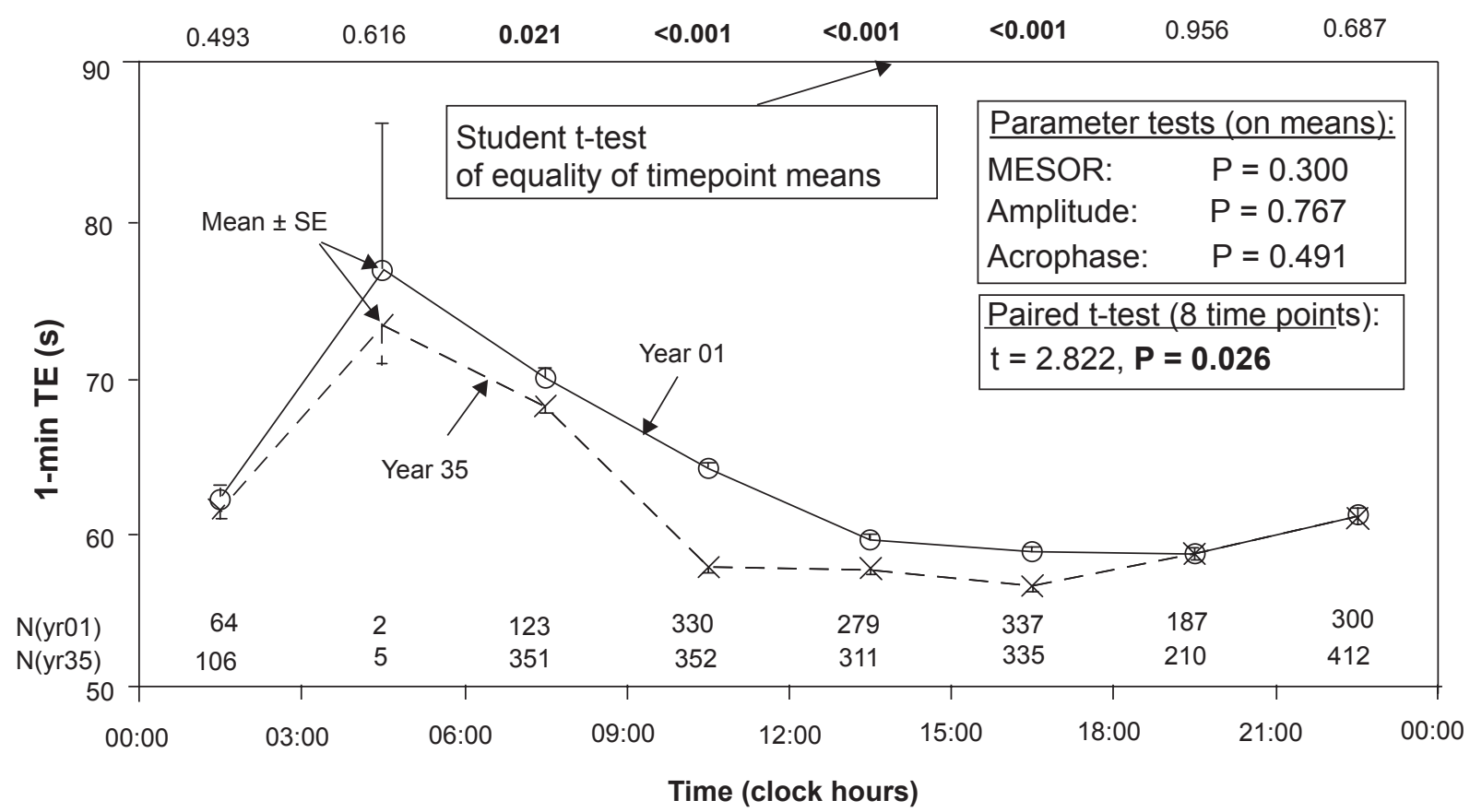

Figure 4 The data of the first and last years of I-minute estimation were stacked along the 24-hour scale. Whereas parameter tests did not detect any change in the characteristics of the 24-hour synchronized rhythm, a paired t-test comparing eight 3-hourly mean values shows a difference below the $5 \%$ level. Moreover, Student's t-test on data in each of 8 equidistant bins reveal that at certain circadian stages, I minute passed faster in the last year than in the first year (year 35 vs year I). This difference was statistically significant at all test times between $06: 00$ and 18:00 (in some of them with $P<0.001$ ), but was not found between I8:00 and 06:00, suggesting that the change in I-minute time estimation with age is circadian stage-dependent, with highly significant differences during part of the daily active phase, but not at other circadian times. In RBS, chronomics demonstrate interaction between the circadian rhythm's stage and age.

undefined fraction of $\tau$ s in other physical and biological variables monitored by RBS and others is also differential; it is not conclusive in itself but is desirable for a follow-up by superposed epochs and by comparison of time courses of $\tau \mathrm{s}$ in and around us, whenever rendered possible due to removal and replacement of intermittent $\tau$ s by the sun and earth. Magnetoperiodism coexists and competes with photoperiodism to influence dynamics in the same individual and can dominate in TE in the range of near-transyears, while photoperiodism dominates in the circulation of the same individual in both the para-annual and circadian spectral domains.

In any event, Figure 4 suffices to infer that in the estimation of subjective time different aspects of the body's temporal make-up interact in a circadian stage-dependent way in the case of RBS; hence, age-dependent acceleration in estimation of 1 minute is best specified as to circadian time and probably as to other rhythms' stages so that a different outcome, such as an acceleration vs no age effect, and in another case (HL) opposite inferences, can be taken at face value. On the positive side, the recognition of cycles, including non-photic ones such as transyears, in time estimation that differ from the photic day and year opens new perspectives of how a mental function can be influenced by the solar wind's cyclicities that may have entered the genome, as circadians clearly did (Touitou and Haus 1992; Halberg et al 2003b; Koukkari and Sothern 2006; Refinetti 2006). The importance of nonphotic cycles beyond those in the estimation of 1 minute is evident from those influencing sudden death (Halberg et al 2006), suicide (Gordon and Berk 2003; Berk et al 2006; Cornélissen and Halberg 2006; Shumilov et al 2008; Chernouss et al pers comm), terrorism (Cornélissen et al 2007; Grigoryev and Vladimirskii 2007; Halberg et al 2007; Wendt 2007), and psychophysiology more generally (Persinger 1987; Oraevskii et al 1998; Breus et al 2002; Palmer et al 2006).

In a follow-up study focusing on the years intervening between ages 25 and 60, opposite effects at different circadian test times could be validated with statistical significance. These findings extend the scope of the comparison of the first and the last year of a 36-year record, which latter sufficed to show that one can have different results 
Spectrogram of 1-minute time estimation during 35 years

a

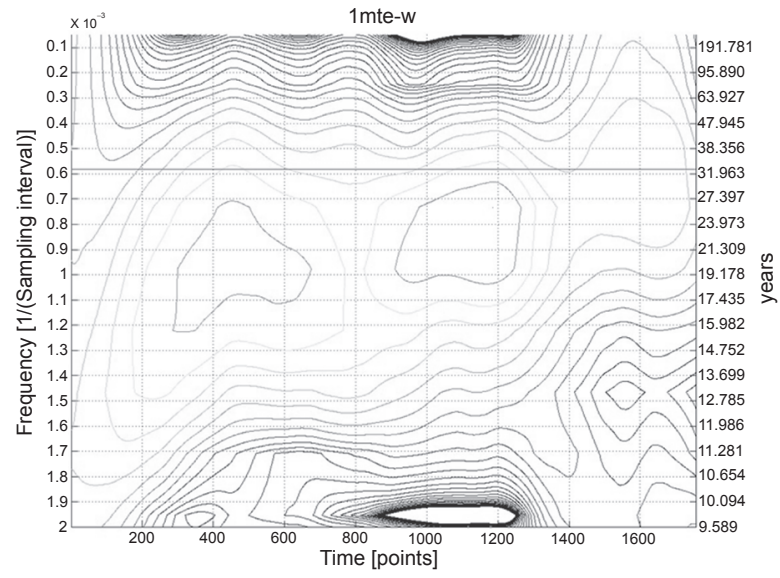

1 mte-w

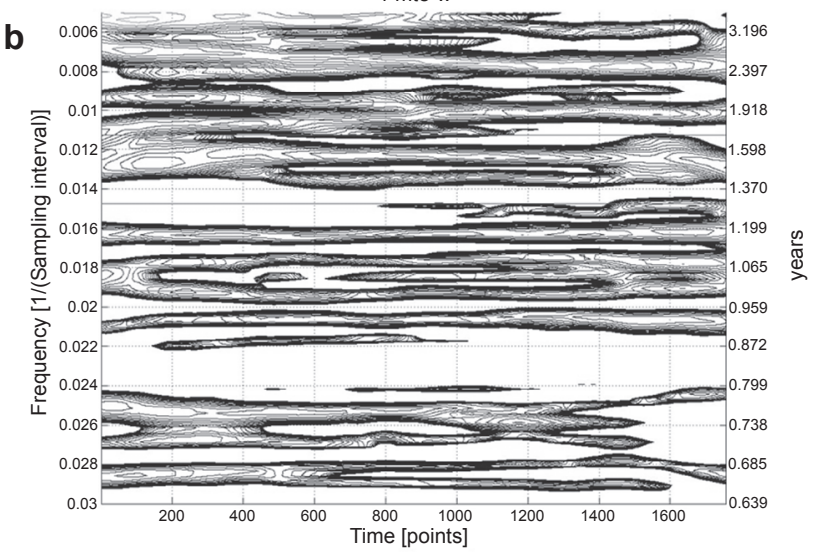

Spectrogram of 1-minute time estimation during 35 years
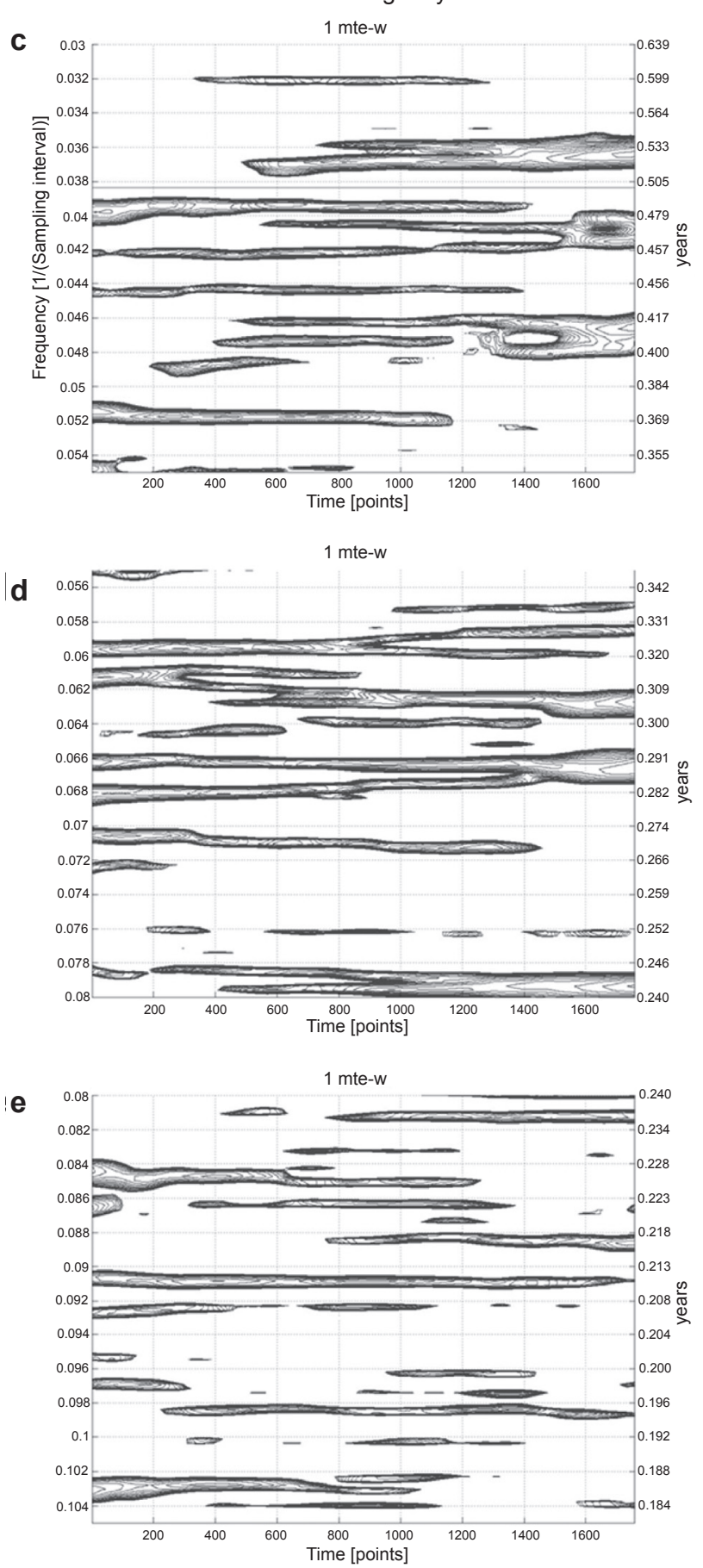

Figure 5 Spectrograms of I-minute estimations around the clock for 35 years, with time ( 35 years) on the abscissa and frequency on the ordinate. 5 a shows a very prominent about ( ) 10-year period, an $\sim 21$-year or even longer period, with changes in its location along the frequency ordinate from the first $\sim 17.5$ years in the left half of the graph, to the next $\sim 17.5$ years in the right half of the figure. Figures $5 \mathrm{~b}$ and in particular $5 \mathrm{c}$ and $5 \mathrm{~d}$ visualize the aeolian character of the spectral components. Many of them are intermittent, changing in frequency and amplitude when present, a fleeting, nonstationary behavior. Whether the failure to detect a component at a given time is due to its absence or to its being buried in noise cannot be decided. 
concerning aging, depending on when along the scale of a day, 1 minute is estimated by counting. A 1-minute duration passed faster at 60 vs 25 years of age at some circadian stages, eg, between 09:00 and 12:00, while at other circadian stages no difference or an opposite trend between 18:00 and 21:00 ( $\mathrm{r}=0.400, \mathrm{P}=0.010)$ was detected. The implication of this finding regarding experimental method is very much broader.

If one examines the change with age of hormones in women, one finds an increase $(\mathrm{P}<0.001)$ for $\mathrm{LH}$ and a decrease for E2 ( $\mathrm{P}<0.001)$ (Halberg et al 1981). Decreases are also found for aldosterone, melatonin and in particular for dehydroepiandrosterone sulfate (Halberg et al 1981; Cornélissen et al 2000). Accordingly, a change in amplitude with age, ceteris paribus, will involve necessarily as a function of age opposite results at the circadian peak versus trough: an increase in amplitude will have a corresponding increase at the time of circadian peak and a decrease at the time of circadian trough and vice versa in the case of a decrease in amplitude there will be a decrease at the time of circadian peak and an increase at the circadian trough. This applies to circadian rhythms and has been documented in Halberg and colleagues (1981) and Cornélissen and colleagues (2000). Similar effects will apply to any other cycle changing with age and controversies will be unavoidable even if the time of day is fixed but chosen differently in various studies, according to investigators' convenience.

A further complication is also relevant to studies on aging between just reaching maturity and at 60 years of age. A plethora of aeolian cycles, Figure 5, are characteristic of many functions monitored not only by RBS but also on over a dozen other subjects of both genders with decades-long time series. Many of these spectral components are of nonphotic origin, coexisting and competing with, and sometimes replacing the calendar-year component. These cycles constitute pertinent control information and are also of interest in their own right, since some of them are associated with suicide (Cornélissen and Halberg 2006) and sudden cardiac death (Halberg et al 2006).

\section{Conclusion}

Aging can be studied without or with chronomics: so it appears to be the case today. But if opposite inferences are drawn at different circadian stages, as documented herein and earlier for another subject, SBS (Sothern et al 2006), it seems possible that we may generalize and consider requiring the time of day as an indication in all studies of human aging.
This seems indicated based on evidence available today, so that controversies are avoided and expensive long-term studies must not be repeated.

Moreover, an indication of calendar date in any and all studies of aging seems to be similarly required, since some of the cycles documented here and elsewhere can be signatures of environmental periodicities, which latter are recorded by governmental agencies and can thus be consulted and used for computing reference cycles.

For human mental function, there is a saying: Use it or lose it. When to use it, to avoid the loss of cognitive function, and when to treat, is already extensively documented for circadians and may also apply to infradians, for instance, since negative affect is primarily circaseptan periodic, while positive affect is dominantly circadian (Cornélissen et al 2005), as shown herein for mental functioning by the proxy of time estimation.

The amplitudes of the new rhythms mapped may be small, but small amplitudes are compatible with large and important associations (Halberg et al 2003c).

The circadian amplitude in the mental function mapped along the age scale remains large and may serve immediately for timing intervention; timing, like dosing, has demonstrated, albeit as yet not routinely utilized, therapeutic benefit.

\section{Acknowledgments}

US National Institutes of Health (5 K06 GM 013981) (FH), University of Minnesota Supercomputing Institute (GC, FH) supported this work. The author declares no competing financial interests in this work.

\section{References}

Berk M, Dodd S, Henry M. 2006. Do ambient electromagnetic fields affect behaviour? A demonstration of the relationship between geomagnetic storm activity and suicide. Bioelectromagnetics, 27:151-5.

Bingham C, Arbogast B, Cornélissen Guillaume G, et al. 1982. Inferential statistical methods for estimating and comparing cosinor parameters. Chronobiologia, 9:397-439.

Breus TK, Chibisov SM, Baevsky RM, et al. 2002. The chronostructure of heart biorhythms under effects of external environment factors. Moscow: Russian University of People's Friendship, Polygraph Service.

Burioka N, Cornélissen G, Maegaki Y, et al. 2005. Approximate entropy of the electroencephalogram in healthy awake subjects and absence epilepsy patients. Clin EEG Neurosci, 36:188-93.

Cornélissen G, Halberg F. 2005. Chronomedicine. In: Armitage P, Colton T (eds). Encyclopedia of Biostatistics, 2nd ed. Chichester, UK: John Wiley and Sons Ltd. p. 796-812.

Cornélissen G, Halberg F. 2006. Chronomics of suicides and the solar wind. Br J Psychiatry, 189:567-8. [Reply to Salib E, Cortina-Borja M. 2006. Effect of month of birth on the risk of suicide. Br J Psychiatry, 188:416-22.]

Cornélissen G, Halberg F, Burioka N, et al. 2000. Do plasma melatonin concentrations decline with age? [Letter to the editor re: Zeitzer JM, Daniels JE, Duffy JF, et al. 1999. Do plasma melatonin concentrations decline with age? Am J Med, 107:432-36.] Am J Med, 109:343-4. 
Cornélissen G, Halberg F, Wendt HW, et al. 2007. Weak magnetoperiodism rather than socio-photo-thermoperiodism characterizes human terrorism detection of about 1.3-year aeolian transyear but not precise 1.0-year cycle. Proc. 8th Intl Congress "Health and education millennium", Moscow, Russia, Nov 14-17, 2007, pp. 77-80.

Cornélissen G, Hillman D, Katinas GS, et al. 2002. Geomagnetics and society interact in weekly and broader multiseptans underlying health and environmental integrity. Biomed Pharmacother, 56(Suppl 2):319s-26s.

Cornélissen G, Watson D, Mitsutake G, et al. 2005. Mapping of circaseptan and circadian changes in mood. Scripta medica, 78:89-98.

Eagleman DM, Tse PU, Buonomano D, et al. 2005. Time and the brain: how subjective time relates to neural time. $J$ Neurosci, 25:10369-71

Fraisse P. 1963. The Psychology of Time. New York: Harper and Row.

Geissler H-G, Reschke K. 1987. Psychophysiologische Grundlagen mentaler Prozesse. Leipzig: Karl-Marx-Universität.

Ghata J, Halberg F, Reinberg A, et al. 1968. Rythmes circadiens désynchronisés (17-hydroxycorticostéroïdes, température rectale, veille-sommeil) chez deux sujets adultes sains. Ann Endocrinol (Paris), 29:269-70.

Glicksohn J. 1992. Subjective time estimation in altered sensory environments. Environ Behav, 24:634-52.

Gordon C, Berk M. 2003. The effect of geomagnetic storms on suicide. S Afr Psychiatry Rev, 6:24-7.

Grigoryev PY, Vladimirskii BM. 2007. The cosmic weather affects the terrorist activity. Uchenye zapiski Tavricheskogo Natsionalnogo Universiteta im V.I. Vernadskogo, Series "Biology, Chemistry" 20(59)(No 1):28-46.

Halberg E, Halberg J, Halberg Francine, et al. 1981. Familial and individualized longitudinal autorhythmometry for 5 to 12 years and human age effects. J Gerontol, 36:31-3.

Halberg F. 1968. Physiologic considerations underlying rhythmometry, with special reference to emotional illness. Symposium on Biological Cycles and Psychiatry. In: Symposium Bel-Air III. Cycles biologiques et psychiatrie/publié sous la direction du professeur J. de Ajuriaguerra. Geneva: Georg/Paris: Masson et Cie. pp. 73-126.

Halberg F. 1980. Chronobiology: methodological problems. Acta Med Rom, 18:399-440.

Halberg F, Cornélissen G, Bingham C, et al. 2003c. Chronomics: Imaging in time by phase synchronization reveals wide spectral-biospheric resonances beyond short rhythms. ("Wenn man über kurze Rhythmen hinausgeht") In memoriam - lost future: Dr-Ing. habil. Dr rer. nat. Barbara Schack: 1952-2003. Neuroendocrinol Lett, 24:355-80.

Halberg F, Cornélissen G, Conti A, et al. 2001a. The pineal gland and chronobiologic history: mind and spirit as feedsidewards in time structures for prehabilitation. In: Bartsch C, Bartsch H, Blask DE, et al. (eds). The Pineal Gland and Cancer: Neuroimmunoendocrine Mechanisms in Malignancy. Heidelberg: Springer; pp. 66-116.

Halberg Franz, Cornélissen G, Katinas G, et al. 2003a. Transdisciplinary unifying implications of circadian findings in the 1950s [online] J Circadian Rhythms, 1(2):61. Accessed on Oct 10, 2008. URL: http:// www.jcircadianrhythms.com/content/pdf/1740-3391-2-3.pdf.

Halberg F, Cornélissen G, Katinas G, et al. 2006. Chronobiology's progress: season's appreciations 2004-2005. Time-, frequency-, phase-, variable-, individual-, age- and site-specific chronomics. $J$ Appl Biomed, 4:1-38.

Halberg F, Cornélissen G, Schack B, et al. 2003b. Blood pressure self-surveillance for health also reflects 1.3-year Richardson solar wind variation: spin-off from chronomics. Biomed Pharmacother, 57(Suppl 1):58s-76s.

Halberg F, Cornélissen G, Sonkowsky RP, et al. 1998. Chrononursing (chronutrics), psychiatry and language. New Trends Exp Clin Psychiatry, 14:15-26.

Halberg F, Cornélissen G, Sothern RB, et al. 1981. International geographic studies of oncological interest on chronobiological variables. In: Kaiser H, (ed). Neoplasms - Comparative Pathology of Growth in Animals, Plants and Man. Baltimore: Williams and Wilkins. pp. 553-96.
Halberg F, Cornélissen G, Sothern RB, et al. 2007. Do unseen, very weak magnetic mechanisms contribute to terrorism in wobbly spectral windows? Proc. 8th Intl Congress "Health and education millennium", Moscow, Russia, Nov 14-17, 2007, pp. 63-6.

Halberg F, Cornélissen G, Watanabe Y, et al. 2001b. Near 10-year and longer periods modulate circadians: intersecting anti-aging and chronoastrobiological research. J Gerontol A Biol Sci Med Sci, 56:M304-24.

Halberg F, Johnson EA, Nelson W, et al. 1972. Autorhythmometry-procedures for physiologic self-measurements and their analysis. Physiol Tchr, $1: 1-11$.

Halberg F, Reinberg A. 1967. Rythmes circadiens et rythmes de basses fréquences en physiologie humaine. J Physiol (Paris), 59:117-200.

Halberg F, Siffre M, Engeli M, et al. 1965. Étude en libre-cours des rythmes circadiens du pouls de l'alternance veille-sommeil et de l'estimation du temps pendant les deux mois de séjour souterrain d'un homme adulte jeune. CR Acad Sci (Paris), 260:1259-62.

Hillman DC, Siffre M, Milano G, et al. 1994. Urinary about-84-hour (circasemiseptan) variations of a woman isolated in a cave and cosmic ray effects. New Trends Exp Clin Psychiatry, 10:173-8.

Koukkari WL, Sothern RB. 2006. Introducing Biological Rhythms: A primer on the temporal organization of life, with implications for health, society, reproduction and the natural environment. New York: Springer.

MacLeod RB, Roff MF. 1935. An experiment in temporal disorientation. Acta Psychologica, 1:381-422.

Oraevskii VN, Kuleshova VP, Gurfinkel I, et al. 1998. Medico-biological effect of natural electromagnetic variations. Biofizika, 43(No 5):844-8.

Otsuka K, Cornélissen G, Halberg F. 1997. Circadian rhythmic fractal scaling of heart rate variability in health and coronary artery disease. Clin Cardiol, 20:631-8.

Palmer SJ, Rycroft MJ, Cermack M. 2006. Solar and geomagnetic activity, extremely low frequency magnetic and electric fields and human health at the Earth's surface. Surv Geophys, 27:557-95.

Persinger MA. 1987. Geopsychology and geopsychopathology: mental processes and disorders associated with geochemical and geophysical factors. Experientia, 43:92-104.

Piaget J. 1946. Le développement de la notion de temps chez l'enfant. Paris: Presses Universitaires de France.

Refinetti R. 2006. Circadian Physiology. 2nd ed. Boca Raton, Florida: CRC Press.

Refinetti R, Cornélissen G, Halberg F. 2007. Procedures for numerical analysis of circadian rhythms. Biol Rhythm Res, 38:275-325.

Sanchez de la Peña S, Halberg F, Galvagno A, et al. 1989. Circadian and circaseptan (about-7-day) free-running physiologic rhythms of a woman in social isolation. Proc. 2nd Ann. IEEE Symp. on Computer-Based Medical Systems, Minneapolis, June 26-27, 1989. Washington DC: Computer Society Press. pp. 273-8.

Shumilov OI, Kasatkina EA, Masloboev VA, et al. 2008. Seasonal patterns of suicides, cardiovascular deaths and seismic activity at high latitudes and their coupling with the seasonal variation of the geomagnetic activity. Geophys Res Abs, 10:EGU2008-A-02867.

Siffre M, Reinberg A, Halberg F, et al. 1966. L'isolement souterrain prolongé. Étude de deux sujets adultes sains avant, pendant et apres cet isolement. Presse Méd, 74:915-9.

Sothern RB, Katinas GS, Cornélissen G, et al. 2004. A 38-year record, albeit informative, is not yet enough: womb-to-tomb monitoring is overdue. Appendix 2 of Halberg F, Cornélissen G, Regal P, et al. Chronoastrobiology: proposal, nine conferences, heliogeomagnetics, transyears, near-weeks, near-decades, phylogenetic and ontogenetic memories. Biomed Pharmacother, 58(Suppl 1):S179-86.

Sothern RB, Katinas GS, Cornélissen G, et al. 2007. Differential congruence of periods in helio- and/or geomagnetics and in human psychophysiology. PS-074, Proc, 2nd World Congress of Chronobiology, Nov 4-6, 2007, Tokyo, Japan. p. 98.

Sothern SB, Sothern RB, Katinas GS, et al. 2006. Sampling at the same clock-hour in long-term investigation is no panacea. Proc, Intl Conf on the Frontiers of Biomedical Science: Chronobiology, Chengdu, China, Sept 24-26, 2006, pp. 208-11. 
Stephens G, Halberg F. 1965. Methodological aspects of human time estimations with special references to 24-hour synchronized circadian rhythms. Nursing Res, 14:310-7.

Tarquini B, Cornélissen G, Perfetto F, et al. 1997. Chronome assessment of circulating melatonin in humans. In vivo, 11:473-84.

Touitou Y, Haus E (eds). 1992. Biological Rhythms in Clinical and Laboratory Medicine. Berlin: Springer-Verlag.
Wendt HW. 2007. Interplanetary magnetic field (IMF) polarity, collective emotions and entropy changes of random event generators. Bulletin of the People's Friendship University of Russia, Proc, 8th Intl Congress "Health and education millennium", Moscow, Russia, November 14-17, 2007, pp. 81-4.

Wever RA. 1979. The Circadian System of Man: Results of Experiments under Temporal Isolation. New York: Springer-Verlag. 
